\title{
The mould for production of plastic spout cap with internal thread by injection moulding
}

\author{
Vladimír Bulej ${ }^{1, *}$, Nadežda Čuboňová ${ }^{1}$, Manfred Eberth $^{1}$, and Karol Vasilko ${ }^{2}$ \\ ${ }^{1}$ University of Žilina, Faculty of Mechanical Engineering, Department of Automation and Production \\ Systems, Univerzitna 1, SK-010 26, Zilina, Slovakia \\ ${ }^{2}$ Technical University of Košice, Faculty of Manufacturing Technologies of the Technical University \\ of Kosice with a seat in Prešov, Bayerova 1, SK-080 01, Prešov, Slovakia
}

\begin{abstract}
The main aim of this article is the mould design for production of plastic spout cap with inner thread by injection moulding technology. There are described the basic steps of whole design process with respect to fulfil all technology and functionality requirements. The application of hot runner system as well as hybrid ejection system based on rotary cores and stripper plate can be considered as the main innovative features of the designed mould. The mould flow analysis was carried out for the functionality demonstration.
\end{abstract}

Keywords: injection moulding technology, hot runner system, rotary cores

\section{Introduction}

Injection moulding technology grows very fast in recent decades. The possibilities and applications for utilizing injection moulding to produce plastic parts are seemingly infinite and offer manufacturers a cost effective method for producing reliable components [1-3]. Nowadays many components previously made of metallic materials are replaced by plastics thanks to the new technologies and improved material properties [4-8]. That is also the reason why we can meet plastics in many areas as well as in common usage at home $[9,10]$. Reasons that injection moulding is so popular include: capability of high production rates, simple to complicated shapes are possible, high tolerances can be maintained, a wide range of materials and extremely cost efficient with low labour rates.

The mould is the key element and it is unique for each product. Its design process is accompanied by a lot of calculations and analyses to identify possible errors already during the preproduction phase and thus affect the final product quality [11]. Time spent during the designing process will save later costs for additional adjustment of the mould. The standard moulds are mostly composed from two parts with a sliding ejection system. Their gating system is based on so-called cold runner system. The result of such mould is set of final parts normally connected together by sprue (the waste). The sprue is typically removed by additional manufacturing process - cutting, what has the negative influence on usability of the melted material, the energy balance as well as on final efficiency of whole process. The

\footnotetext{
* Corresponding author: vladimir.bulej@fstroj.uniza.sk

Reviewers: Tomasz Kmita, Radek Knoflíček
} 
designers of injection moulds are then utilizing progressive methods of mould design [12]. One of these methods is also the application of so-called hot runner system, which eliminates the waste of materials and the need for separation of individual parts as well.

\section{Design of injection mould for part with inner thread}

The injection mould design must be solved according to fulfil customer requirements and demands as well as technological requirements and with respect to available machinery equipment of the company, the data written in product drawing, the additional information about material, quantity of production.

\subsection{Product for injection moulding technology}

This article describes the design of the injection mould for production of Spout Cap 28/410 for PET bottles (Fig. 1) designed by company YORKER Packaging from low-density polyethylene [13]. Weight of this component is $m=3.53 \mathrm{~g}$ and the volume $V=3735.15 \mathrm{~mm}^{3}$. It was necessary to solve the right method for part ejection from the mould cavity with respect to the inner thread on a cylindrical surface.
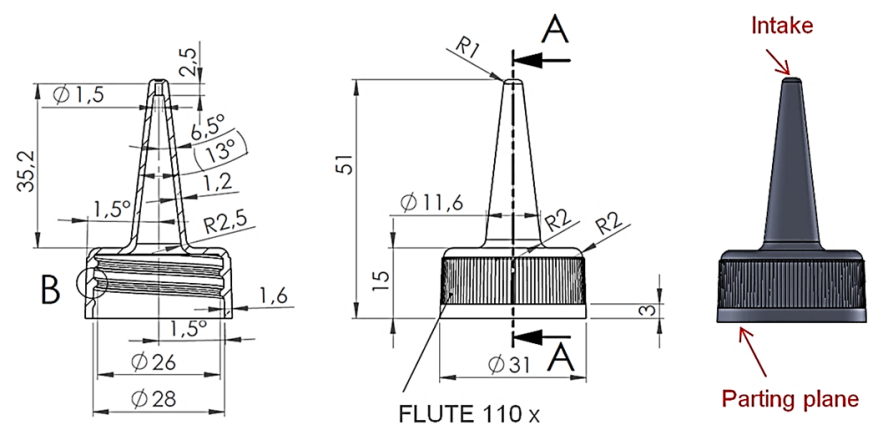

Fig. 1. The final product for injection moulding technology - Spout Cap 28/410 [13]

As it was mentioned above, the final product will be made of low-density polyethylene (list of basic properties in Table 1). Among polyolefin, polyethylene (PE) is one of the most widely used plastics, as the molecular structure of PE is simple and it has good chemical resistance and processing properties.

Table 1. Basic material parameters and properties for product Spout Cap 28/410 [13]

\begin{tabular}{|c|c|c|c|c|c|}
\hline Material & \multicolumn{5}{|c|}{ LDPE (Low Density Polyethylene) } \\
\hline Parameter & Unit & Value & Parameter & Unit & Value \\
\hline Density & {$\left[\mathrm{g} \cdot \mathrm{cm}^{-3}\right]$} & $0.91-0.94$ & Shrinkage & {$[\%]$} & $1.5-5$ \\
\hline Melt Temperature & {$[\mathrm{K}]$} & $450-550$ & Injection Pressure & {$[\mathrm{MPa}]$} & $50-150$ \\
\hline Mold Temperature & {$[\mathrm{K}]$} & $290-345$ & Injection Speed & \multicolumn{2}{|c|}{ Fast speeds } \\
\hline
\end{tabular}

PE can be classified into ultrahigh-molecular-weight polyethylene (UHMWPE), highdensity polyethylene (HDPE), low-density polyethylene (LDPE), and so on. The LDPE we can find in wide variety of products. LDPE is produced by the polymerization of ethylene at high pressure and temperature, the material is semicrystalline-crystalline. The crystallinity level is low because of chain branching. The material is tough but possesses moderate tensile properties and exhibits creep. However, it has good impact and chemical resistance. It is an 
easy flow material because of long chain branching. Commercial materials have densities in range of $0.91-0.94 \mathrm{~g} . \mathrm{cm}^{-3}$. LDPE is permeable to gases and vapours [5]. Very close tolerances are not possible with this material and its relatively large coefficient of thermal expansion makes it less suitable for long term applications. Shrinkage is of the order of $0.02-0.05$ $\mathrm{mm} . \mathrm{mm}^{-1}(1.5-5 \%)$. Actual shrinkage values are dependent on the moulding conditions. LDPE is resistant to many solvents at room temperatures but aromatic and chlorinated hydrocarbons cause swelling. Like HDPE, it is also susceptible to environmental stress cracking. For this material is recommended the injection pressure between 50 and $150 \mathrm{MPa}$ and fast injection speeds [5,7,11]. Drying before processing is not necessary. All conventional types of runners and gates may be used, so LDPE is well suited also for hot runner systems.

\subsection{Machinery}

Standard injection moulding machine consists of two main parts - an injection unit and a clamping unit in general. We choose an injection moulding machine ENGEL victory 60/200 ecodrive (Fig. 2) with clamping force of $600 \mathrm{kN}$ and injection unit up to $200 \mathrm{MPa}$. Its basic technical parameters are shown in table 2.

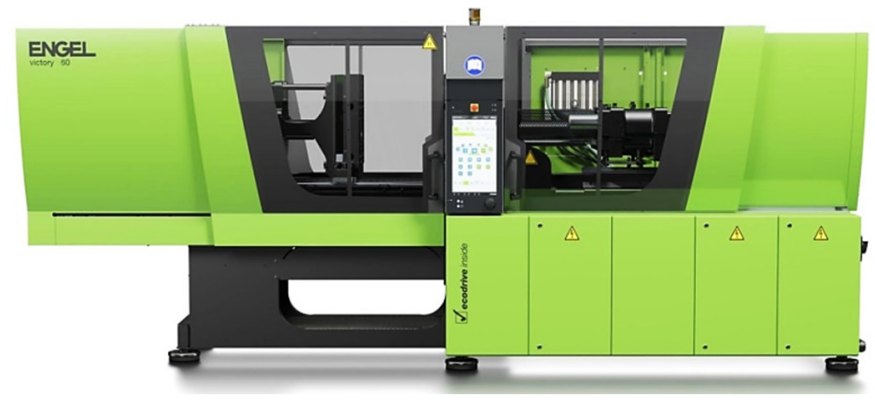

Fig. 2. Injection moulding machine ENGEL victory 60/200 [14]

The comparatively small injection moulding machine is due to a special design feature of the ENGEL victory machine, so-called "tie-bar-less clamping unit". Because there are no tie bars in the way, the mould mounting platens can be fully used up to their very edges. Motors for core-pulls or other functional components can even jut out beyond that. Further benefits of the tie-bar-less technology include fast mould set-up processes and efficient automation solutions because robots can access the mould area directly from the side without having to circumvent any obstacles. The patented Force Divider flexlink ensures high precision and process consistency [14].

Table 2. Basic parameters of injection moulding machine ENGEL victory 60/200 [14]

\begin{tabular}{|c|c|c|c|c|c|}
\hline Injection machine & \multicolumn{5}{|c|}{ ENGEL victory 60/200 ecodrive } \\
\hline Parameter & Unit & Value & Parameter & Unit & Value \\
\hline Clamping force & {$[\mathrm{kN}]$} & 600 & Injection pressure max. & {$[\mathrm{MPa}]$} & 200 \\
\hline Opening stroke max. & {$[\mathrm{mm}]$} & 450 & Volume / one stroke & {$\left[\mathrm{cm}^{3}\right]$} & 78 \\
\hline Max. mould weight & {$[\mathrm{kg}]$} & 450 & Injection speed max. & {$\left[{\left.\mathrm{mm} . \mathrm{s}^{-1}\right]}^{-1}\right.$} & 113 \\
\hline $\begin{array}{c}\text { Mould mounting platens } \\
\text { (max. dimensions) }\end{array}$ & {$[\mathrm{mm}]$} & $670 \times 600$ & $\begin{array}{c}\text { Injection screw } \\
\text { diameter }\end{array}$ & {$[\mathrm{mm}]$} & 25 \\
\hline
\end{tabular}




\subsection{Mould design}

The design process consists of several steps $[13,15]$ :

- definition of parting plane - how the products will be placed inside the mould cavity,

- definition of mould multiplicity - the number of product done in one sequence,

- shrinkage calculation (not mentioned in article),

- design of the inlet system, ejector system and tempering system.

\subsubsection{Parting plane}

The parting or dividing / split plane must be selected at the beginning together with intake position. It defines the surface where are touching both main mould plates while the mould is closed and fixed by clamping unit. In our case we decided to align it with the bottom edge of the cap as is shown in figure 1 - right. In the mould design will be used the abovementioned hot runner system, and a system of movable cores with ejector stripper board.

\subsubsection{Mould multiplicity}

Mould multiplicity refers to the number of products which can be produced per one working cycle. For calculation of multiplicity we must take into account two main criteria:

\section{a) Multiplicity according to the clamping force}

This method is based on the size of buoyant force caused by the melted material in the parting plane which must be restrained by clamping unit of the injection machine [7].

$$
n_{c f}=\frac{0.8 \cdot F_{c}}{A_{\text {real }} \cdot p_{\text {inj }}}=\frac{0.8 \cdot 600000 \mathrm{~N}}{754.7 \mathrm{~mm}^{2} \cdot 100 \mathrm{MPa}}=\frac{480000 \mathrm{~N}}{75470 \mathrm{~N}}=6.36 \approx 6
$$

Where: $\quad n_{c f}$ - multiplicity according the clamping force [ - ],

$F_{c} \quad$ - clamping force $[\mathrm{N}]$,

$A_{\text {real }}$ - area of a whole cavity cross-section in parting plane $\left[\mathrm{mm}^{2}\right]$ (equation 2),

$p_{i n j} \quad$ - injection pressure [MPa],

$A_{\text {part }}$ - area of one part cross-section projected into the parting plane $\left[\mathrm{mm}^{2}\right]$,

$A_{\text {intake }}$ - cross-section area of intake projected into the parting plane $\left[\mathrm{mm}^{2}\right]$;

In our case (for hot runner system) is equal to 0 ,

$d_{\text {part }}$ - diameter of the product projected into the parting plane [mm].

$$
A_{\text {real }}=A_{\text {part }}+A_{\text {intake }}=A_{\text {part }}+0=\frac{\pi \cdot d_{\text {part }}^{2}}{4}=\frac{\pi \cdot(31 \mathrm{~mm})^{2}}{4}=754.7 \mathrm{~mm}^{2}
$$

\section{b) Multiplicity according to the maximum volume of melted material injected in one cycle}

This is based on ratio between the maximal and needed volume of injected material [7].

$$
n_{V}=\frac{V_{\text {max }}}{V_{\text {real }}}=\frac{78000 \mathrm{~mm}^{3}}{3735.15 \mathrm{~mm}^{3}}=20.8 \approx 20
$$

Where: $n_{V} \quad$ - volume multiplicity [ - ],

$V_{\max }$ - maximal volume injected within one stroke of piston $\left[\mathrm{mm}^{3}\right]$,

$V_{\text {real }}$ - real volume of a product (include the part of intake) $\left[\mathrm{mm}^{3}\right]$ (equation 4),

$V_{\text {part }}$ - volume of one part $\left[\mathrm{mm}^{3}\right]$,

$V_{\text {intake }}$ - volume of intake per 1 part $\left[\mathrm{mm}^{3}\right]$; for hot runner system is equal to 0 , 


$$
V_{\text {real }}=V_{\text {part }}+V_{\text {intake }}=3735.15 \mathrm{~mm}^{3}+0 \mathrm{~mm}^{3}=3735.15 \mathrm{~mm}^{3}
$$

According to get high quality products we will choose from value of both criteria the lower one (result from equations 1 and 3). We can see that the lower one is the multiplicity according to the clamping force. So our mould will be designed with multiplicity equal to 6 (6 products per one working cycle).

$$
n_{\text {FINAL }}=\min \text { of }\left(n_{c f} ; n_{V}\right)=n_{c f}=6
$$

\subsubsection{Intake system}

Intake (or gatting) system connects the end of injection nozzle with the mould cavity by one or more channels. The main functional task of intake system is achieving homogenous filling of whole mould cavity. There should be achieved easy removal of final product from the mould as well. A second aim is to minimize the volume of the sprue. Thanks to hot runner system (Fig. 3) we can reduce the sprue to absolute possible minimum.

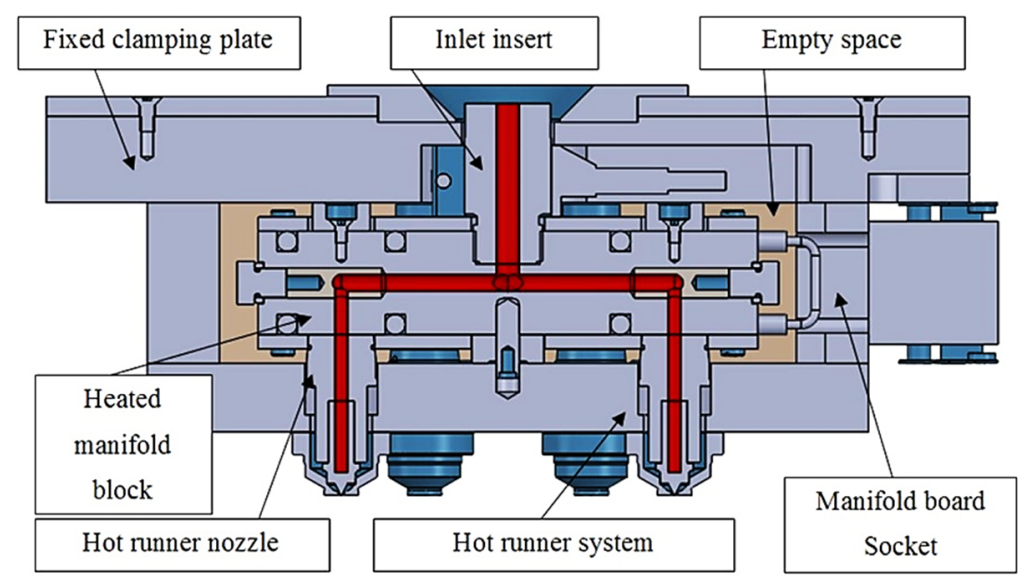

Fig. 3. Cross section and principle of intake system with hot runner nozzles

The principle of the hot runner system is that the melted plastic material remains in the whole intake system in the liquid state. This allows us to use of small cross section for the mouth with minimal or no cold channels what means minimal or no waste of material. Normally the nozzle is directly connected to the mould cavity. In the nozzle centre there is a shut-off valve needle. The connection of nozzle and final product is shown below (Fig. 4).

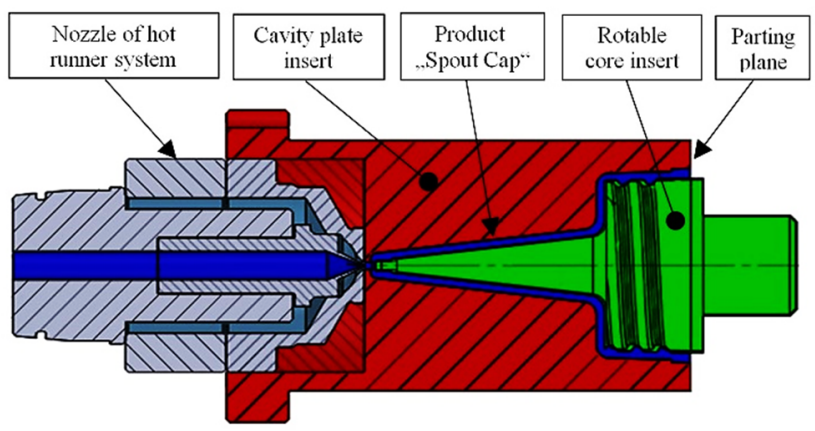

Fig. 4. The cross-section Hot runner system 
The manifold with heated distribution channels is used in combination with a heated and insulated nozzle pre-chamber. Their shape is related to the required position of intake channels toward the fitting nozzles - shape called I, H, X, Y and others. For our system we designed hexagonal manifold with six nozzles as is shown in figure 5, right.
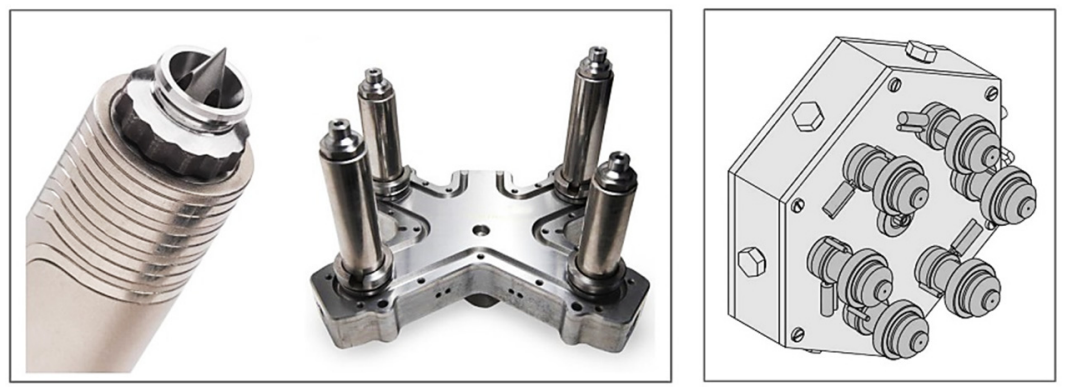

Fig. 5. Hot runner system: an example of hot runner system - a nozzle and nozzles in manifold (left) and our design of hexagonal manifold with 6 nozzles (right)

\subsubsection{Ejection system}

In general, for removing of final product from the mould cavity, there exist several kinds of ejection systems, e.g. pin ejection, sleeve ejection, stripper plate ejection, blade ejection, rotation core ejection, air ejection, etc. An internal thread form is basically an undercut that does not allow free ejection from the mould. Besides relatively rare method of unscrewing by hand and direct stripping of flexible parts with shallow thread profile there are common two different functional principles of inner threaded parts removing:

- the systems with collapsible threaded core and two-stage ejector - can be used to mould internal thread forms and freely eject small to medium size parts,

- the system with rotating cores driven by gear transmission and stripper plate - this system is based on transformation of linear motion generated by clamping mechanism into the combined rotational and linear motion of core inserts.

Finally we decided for the second alternative, so our mould is designed as hybrid system composed from rotating cores driven by gear transmission and stripper plate. Next step is therefore the design of gear transformation mechanism (see figure 6).
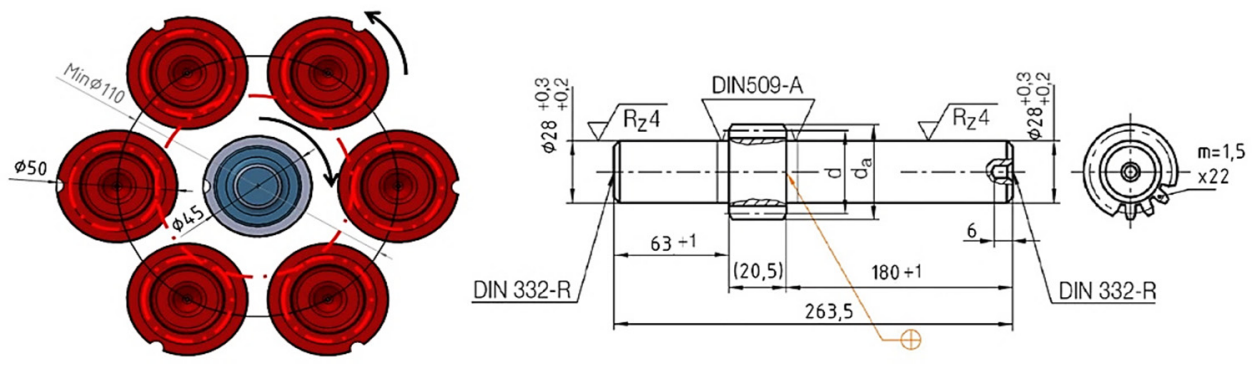

Fig. 6. Transmission driven mechanism for rotating cores motion

The transformation mechanism is composed from the steep lead screw (in our case chosen HASCO Z1500 - [16]) fixed in the axis of static part of mould. The nut combined with pinion gear is supported by bearings inside the moving part of mould. This unit is set to motion by opening of mould. Subsequently the rotational motion is transmitted to the driven gear shafts linked with core inserts arranged in a "planetary" configuration around the central screw according to the mould multiplicity (Fig. 6, left). The calculation of gear transmission system 
is based on the diameter of cavity plate inserts (Fig. 6, left - 6 circles) as well as the maximum diameter of steep lead screw HASCO Z1500 [16].

$$
\begin{gathered}
d_{1}=m \cdot z_{1}=1.5 \cdot 22=33 \mathrm{~mm} \quad d_{2}=m . z_{2}=1.5 \cdot 55=82.5 \mathrm{~mm} \\
a=\frac{d_{1}+d_{2}}{2}=\frac{33+82.5}{2}=57.75 \mathrm{~mm}
\end{gathered}
$$

Where: $d_{1,2}$ - pitch diameter of gear 1 or $2[-]$,

$z_{1,2}$ - teeth number of gear 1 or $2[-]$,

$m$ - module of gears tooth-size,

$a$ - the shortest distance between the gears axes [mm].

As the transmission elements were chosen the gears HASCO Z1550-28x180 and Z1553$36-20$. Then the module of both gears is set to $m=1.5$ and the teeth number is 22 for the first one and 55 for the second one (pitch circle of both gears is calculated in Eq. 6). Our design of whole ejection system as well as cross-section of whole mould is shown in Fig. 7.

The ends of shafts are guided by the threaded inserts which ensure the helical movement of the core inserts. In exactly defined position of the mould during the opening will start to move also the stripper plate (Fig. 7) which help to eject the products Spout cap.

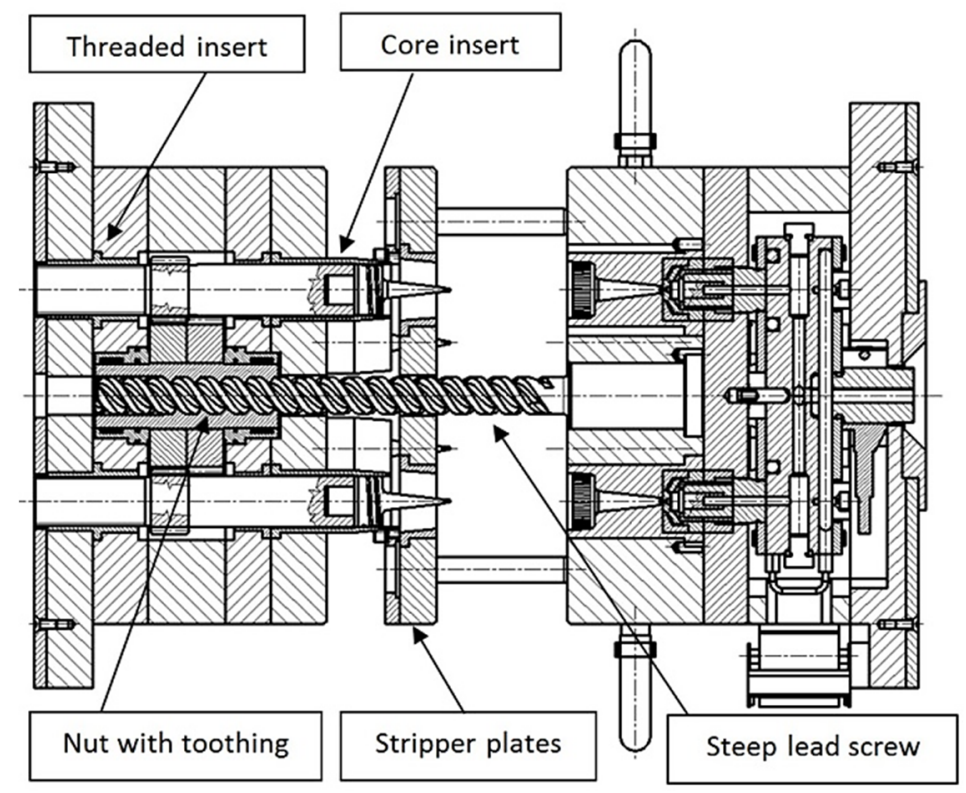

Fig. 7. Final mould design (cross-section view) and ejection system principle

\subsubsection{Mould flow simulation results}

Nowadays, the simulation play very important role in pre-production phase and can have massive influence on the final costs and efficiency of processes [17-20]. SolidWorks Plastics provides an effective injection moulding simulation tools which can help to identify production limits and predict potential failures and consequently eliminate them even in the early stages of product development $[15,21]$. The software is suitable for designers of plastic parts as well as mould tool manufacturers. SolidWorks Plastics is fully integrated with SolidWorks CAD software. Changes are instantly reflected in the 3D model and can easily be passed on to the manufacturability assessment [20-22]. We decided to simulate injection 
moulding process only for one part because there are produced six identical parts with small volume and with using of hot runner system in one cycle. Below there are described the results of filling time, injection pressure and cooling time analyses.

\section{Filling time}

The results of this analysis indicate for what time the mould cavity is filled in with melted plastic material. Various colours display the flow position of melted plastic at regular intervals (Figure 8, left). Using this analysis, we can understand the influence of the intake mouth location. The intake should be placed regarding that the mould is filled evenly (uniform filling) and in the shortest possible time. Further, it is possible to determine where the cold zones (connections) will occur and where the venting slots should be installed [23, 24]. The analysis revealed that the intake position was chosen correctly and the total filling time is about 0.75 seconds. In our case, the risk of cold zones is quite low and the mould should not be aerated.

\section{Filling pressure}

The result of this analysis shows how much pressure will be needed to fill the mould cavity for the over mentioned 0.75 second time period. A maximum pressure of about 35 $\mathrm{MPa}$ is in the mouth of the hot intake as expected, while at the furthest point of the mould it is about $5 \mathrm{MPa}$ (Figure 8, middle). Of course this can be modifying by injection ramp controlled by injection control unit. After first real testing of the mould, it could be determined exactly the pressure profile suitable to get the best results.

\section{Cooling time}

As a result of this analysis, the colour range was again based on which we can determine the need for the tempering system and its location (Figure 8, right). From this analysis, we identified the places that will be needed to cool with parts of the tempering system. The results of the analysis fit quite well with our assumptions. In the area with the coarsest diameter, it will be necessary to temper or, chill the component to reduce the cooling time from about 12 seconds to lower one.
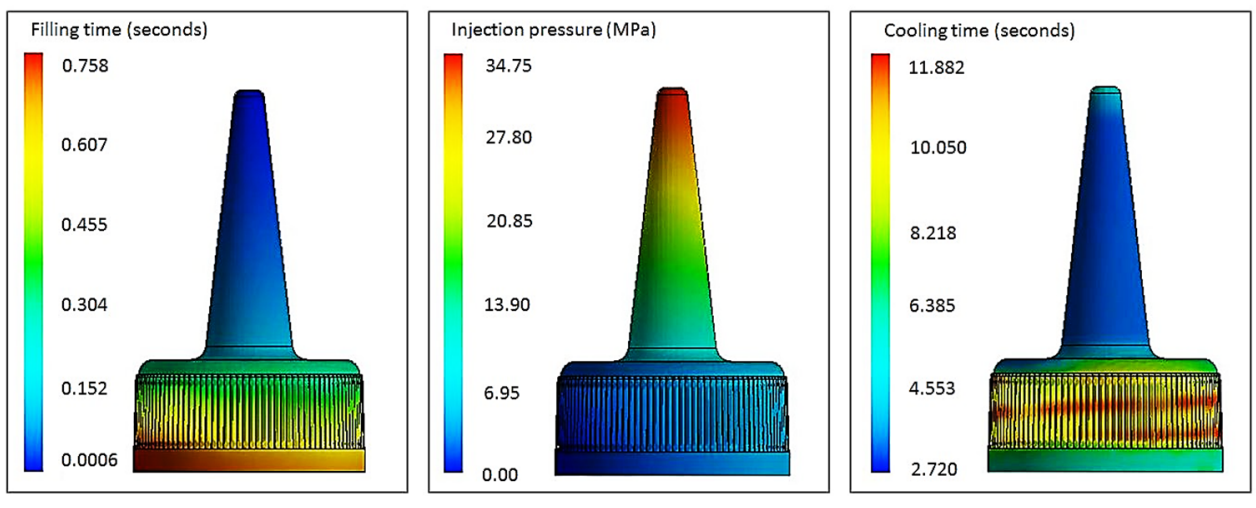

Fig. 8. Simulation results: time of filling (left), injection pressure inside the cavity while filling (middle), time of cooling (right)

The analysis provides much more information about the injection process. However, given the limited scope of this article, only basic parameters have been described. According to the analysis, it can be seen that the filling of the cavity is relatively homogenous, the pressure as well as temperature distribution are within the recommended range. Places where air bubbles will be formed can be resolved by adding venting slots if needed. Cold zones can be removed by appropriate adjustment of the technological parameters (eg. by increasing the melt temperature or injection speed). 


\section{Conclusions}

The main aim of this article was the mould design for selected component Spout cap 28/410 production by injection moulding technology. Regarding to the inner thread on this product it was necessary to solve mainly the gating system and ejection system. The mould design was carry out for injection press ENGEL victory 60/200 ecodrive. Thanks to the used hot runner system we were able to reduce the sprue to absolute possible minimum. Regarding to an internal thread was selected the hybrid or combined ejection system composed from stripper plate and rotary cores driven by gear transmission which is suitable for such kind of products. The final design was verified by simulation in mould flow module of CAD software SolidWorks.

\section{References}

1. D.E. Dimla, M. Camilotto, et al, Design and optimization of conformal cooling channels in injection moulding tools. J. of Mat. Proc. T. 164-165, p. 1294-1300 (2005)

2. S. Marques, A. Fagali de Souza, M. Jackson, I. Yadroitsau, Design of conformal cooling for plastic injection moulding by heat transfer simulation. Polímeros, 25(6), 564-574 (2015)

3. D. Homar, et al, Cooling simulation of conformal cooling injection mould insert produced by hybrid manufacturing. Technological Gazette, 24(4), p. 981-986 (2017)

4. N. Čuboňová, Utilization of genetic alghoritms by the tool path programming. Ann. of DAAAM and Proc. of the Int. DAAAM Symp., 63-64, (2011)

5. J.Wang, D. Chen, S. Wang, et al, Insert injection molding of low-density polyethylene single-polymer composites reinforced with ultrahighmolecular-weight polyethylene fabric. J. of Thermopl. Compos. Mat., 31(8), 1013-1028 (2018)

6. S. Teklehaimanot, Simulation and Design of a plastic injection Mold. (University of Applied Sciences ARCADA, Finland [Degree Thesis], 2011)

7. D. Stančeková, R. Kameník, A. Sapietová, J. Pilc, T. Zlámal, J. Cais, Comparison of properties of steel 100Cr6 and C56E2 in the process of machining. METAL 2017: 26th Int. Conf. on Met. and Mat. p. 819-825, (2017)

8. J. Korzekwa, et al, Electromechanical properties of PLZT x/90/10. Eu. Phys. J: Spec. Top. 154(1), p. 127-130 (2008) DOI: 10.1140/epjst/e2008-00530-5

9. A. Rengevič, M. Fúra, N. Čuboňová, Analysis of printing parameters for production of components with Easy3DMaker printer. Adv. in Sci. and Techn.-Res. J. 10(32), p.1-8, (2016), DOI: 10.12913/22998624/65114

10. A. Rudawska, P. Pawlak, I. Miturska, D. Stančeková, M. Chyra, Comparative analysis of welded and adhesive joints strength made of acid-resistant stainless steel sheets. Adv. in Sci. and Techn.-Res. J. 11(4), p. 97-102 (2017), DOI: 10.12913/22998624/78165

11. M. Bruna, A. Sládek, Hot tearing evaluation of al - based alloys. Man. Techn. 16(2), p. 323-327, 2016

12. D. Stančeková, A. Czán, M. Derbas, Investigation of defects in forging tools by nondestructive detection method. Metal 2013: $22^{\text {nd }}$ Int. Conf. on Metal. and Mat. P. 485490, (2013)

13. M. Skalicky, Mechanical Design of Mould for Plastic Component Produced by Injection Moulding Technology. (University of Žilina, Žilina [Master thesis], 2014)

14. Engel Austria GmbH, ENGEL victory - Machine system with freedom to move. Available on: https://www.engelglobal.com/en/at/solutions/injection-moulding-machines/victory.html 
15. J. Stanček, V. Bulej, Design of driving system for scissor lifting mechanism. Acad. J. of Man. Eng. 13(4) p. 38-43, (2015).

16. Hasco, Z1500 Product info. Available on https://www.hasco.com/hasco/en/Productcatalogue/Z/Demoulding/Gear-products/Transmission-elements/Z1500-d1xp1-L12/p/Z1500_d1xp1_L_12.

17. M. Jančušová, Moulds for processing of plastics (in Slovak). (University of Žilina, Žilina, 2010)

18. Z. Tůma, R. Knoflíček, J. Tůma, F. Bradáč, P. Blecha, The Process Simulation Using by Virtual Reality. Procedia Eng. 69, (2014), DOI: 10.1016/j.proeng.2014.03.084

19. Š S. Václav, J. Jurko, Š. Lecký, Allowance treatment static designed couple and repeatable precision in assembly. MATEC Web of Conferences 137, Art. No. 04007 (2017) DOI: $10.1051 /$ matecconf/201713704007

20. V. Bulej, et al, Study of the Workspace of Hybrid Mechanism Trivariant. App. Mech. a. Mat. 436, p 366-373 (2013), DOI: 10.4028/www.scientific.net/AMM.436.366

21. J. Lipina, V. Krys, R. Pastor, Increasing the Load Capacity of Screw Connections in Parts Produced by the Rapid Prototyping Method. INES 2016 - 20th IEEE Int. Conf. on Int. Eng. Sys. 147-150 (2016)

22. M. Kelemen, T. Kelemenova, I. Virgala, Rapid Control Prototyping of Embedded Systems Based on Microcontroller. Modelling of Mech. and Mechat. S. 96, p. 215-220 (2014), DOI: 10.1016/j.proeng.2014.12.146

23. M. Staněk, D. Maňas, M. Maňas, J. Javorík, Simulation of injection molding process. Proc. of the 13th WSEAS Int. Conf. on Aut. Con., Mod. \& Sim. p. 231-234 (2015)

24. F. Dupret, A. Couniot, et al, Modelling and simulation of injection molding. Rheology Series, 8, p. 939-1010 (1999), DOI: 10.1016/S0169-3107(99)80012-4 